1 DLR, Institut für Physik der Atmosphäre, Oberpfaffenhofen, Federal Republic of Germany

2 DWD, Zentralamt, Offenbach, Federal Republic of Germany

${ }^{3}$ Amt für Wehrgeophysik, Traben-Trarbach, Federal Republic of Germany

${ }^{4}$ Meteorologisches Institut, Universität München, Federal Republic of Germany

\title{
The Front of 8 October 1987 - Predictions of Three Mesoscale Models
}

\author{
H. Volkert ${ }^{1}$, M. Kurz ${ }^{2}$, D. Majewski ${ }^{2}$, T. Prenosil ${ }^{3}$, and A. Tafferner ${ }^{4}$ \\ With 11 Figures
}

Received October 21, 1991

Revised January 20, 1992

\begin{abstract}
Summary
The frontal passage of 8 October 1987, which was extensively sampled during the first intense observation period of the German Front Experiment, is simulated by aid of three mesoscale models. The results are intercompared and held against the manually and objectively analysed observations of the meso- $\alpha$ and meso- $\beta$ scales, respectively. The orographic impact is studied by comparing model runs with full and cut-off Alps. Implications regarding similar efforts in the future conclude the paper.
\end{abstract}

\section{Introduction}

Demands from the numerical modelling community are used as a standard argument in the definition phase of mesoscale field programmes. Data sets with enhanced temporal and spatial resolution are sought as input as well as validation material for modelling studies. As two European examples we mention the Alpine Experiment (ALPEX; Kuettner, 1982, pp. 7-11) and the German Front Experiment 1987 (GFE87). The latter field campaign constituted the major experimental effort within the Forschungsschwerpunkt "Fronten und Orographie" which was supported by the Deutsche Forschungsgemeinschaft. In the initial planning document, Egger (1985, p. 46) stated the necessity of a hierarchy of models in order to improve the understanding of the involved mechanisms. On top of the such a hierarchy he envisaged the regional-scale prediction models, which are used by the German weather services (civilian and military), and research type models, which are capable of recomputing the frontal events captured during the intense observation periods (IOPs) of the experiment.

In a recent review, Keyser and Uccellini (1987) exemplified in considerable depth the great potential offered by regional models (i.e. models concentrating on meso- $\alpha$ scale phenomena and initialized by analyses from the routine radiosonde network or large scale model output) for conducting phenomenological research and case studies. They consider synoptic meteorology as being alive and well (rather than a dying discipline as sometimes stated), although its character is changing irrevocably in response to evolving observational and computational technologies. Three kinds of research approaches are distinguished by Keyser and Uccellini: the first is the direct use of model output to analyse mesoscale phenomena, the second comprises sensitivity studies (mostly through difference fields from computations "with" and "without" the process under consideration), while the third produces detailed diagnostic studies of dynamically relevant quantities which cannot be assessed otherwise. 
The British Meteorological Office fine mesh model was mentioned as the only European example of a regional model with published results in the refereed English-language literature (e.g. McCallum et al., 1983). This does not imply that other European weather services did not develop regional models for operational and research purposes. Gr $\phi$ nås (1989) summarized such efforts. Relevant studies concentrating on meso- $\beta$ scale phenomena, which need sophisticated boundary layer parameterizations, have been conducted very recently by Ballard et al. (1991; UK mesoscale model) and by Bougeault et al. (1991; French mesoscale model PERIDOT).

It is important to distinguish the special class of regional models as defined above from the greater variety of mesoscale models, which mainly deal with certain physical processes in more or less idealized situations. As a recent German example we mention Heimann (1990), who applied a hydrostatic mesoscale model to study the propagation of synthetic cold fronts influenced by orographic and precipitation processes.

Comparison of different numerical models is a natural wish of the modelling community in order to obtain insights in the capabilities of various models. Examples are available for models dealing with different length scales. Arpe et al.(1985) compared the statistical properties of three operational large scale prediction models. Anthes (1983) compiled an extensive review of six then operational and eight research type regional models, which were mainly operated in USA. For micro-physical cloud models a direct comparison of two experimentally well sampled cases has been carried through under the auspices of the World Meteorological Organization (WMO, 1988, pp. 29-50).

The present investigation loosely combines the three areas mentioned: (i) model runs to investigate an experimental IOP of GFE87, (ii) application of (three) regional models as research tools and (iii) intercomparison of the model performances for one particular case. Specifically, the frontal passage of 8 October 1987 (IOP-A) is considered. For observational details see Hoinka and Volkert (1992; from now on referred to as HV92) and Hoinka et al. (1990), Three regional models are applied, namely the Europa-Modell of the Deutscher Wetterdienst (DWD), the Boundary-LayerModel of the Amt fur Wehrgeophysik (AWG) and an isentropic coordinate model, which is used by a group at the Universität München. The results obtained belong to the first two research approaches of Keyser and Uccellini (direct interpretation of model output and sensitivity studies). Furthermore, comparisons with manually and objectively analysed experimental data are undertaken.

The specific objectives of this study are:

- to exemplify the performance of the three models for a special case, which has attracted considerable scientific interest;

- to document the Alpine influence on the model results through control runs using a cut-off model orography; and

- to assess the discrepancies between model results and observations of enhanced spatial and temporal resolution close to the Alps.

Pursuit of these (modest) aims serves several purposes. For example, (a) more stringent evaluations of the models are motivated and (b) the importance of datasets is stressed, which combine truely mesoscale resolution and sufficient spatial and temporal extent to be useful for initialization and evaluation of model results.

The organization of the paper is as follows: in section 2 the models are briefly introduced, section 3 contains the results with special emphasis on the meso- $\alpha$ scale structure of the front, the orographic impact of the Alps and meso- $\beta$ scale details over the north Alpine foreland. Section 4 summarizes the findings and mentions some implications.

\section{The Models}

The main characteristics of the three numerical models used in this study are summarized in Table 1, whereas the respective domains are outlined in Fig. 1. All three models employ the hydrostatic assumption.

The Europa-Modell (EM) of the Deutscher Wetterdienst is certainly the most recently developed and most fully equipped with physical parameterizations of the three competitors. The version applied here covers approximately $25 \%$ of the region used for operational short range forecasts since January 1991. A pressure-based vertical coordinate system (Simmons and Burridge, 1981 ) is used, which consists of 16 terrainfollowing $\sigma$-levels topped by 4 pressure levels. Details concerning the physical parameterizations, 
Table 1. Characteristics of the Three Numerical Mesoscale Models and Features Specific to this Study

\begin{tabular}{|c|c|c|c|}
\hline Name & Europa-Modell & Boundary-Layer-Model & "Theta-Surface-Model" \\
\hline Code & $\mathrm{EM}$ & BLM & TSM \\
\hline Institution & Deutscher Wetterdienst & Amt für Wehrgeophysik & Meteor. Inst. Univ. München \\
\hline $\begin{array}{l}\text { \# gridpoints } \\
(\mathrm{IM} \times \mathrm{JM} \times \mathrm{KM})\end{array}$ & $\begin{array}{l}118,260 \\
(81 \times 73 \times 20)\end{array}$ & $\begin{array}{l}23,970 \\
(47 \times 51 \times 10)\end{array}$ & $\begin{array}{l}140,800 \\
(80 \times 88 \times 20)\end{array}$ \\
\hline$\overline{\Delta x}(\mathrm{~km})$ & 55 & 63 & 45 \\
\hline$\Delta t(\min )$ & 5 & 5 & 1 \\
\hline Vertical coordinate & $\begin{array}{l}\text { hybrid } \\
(16 \sigma+4 p)\end{array}$ & $\eta$ & $\begin{array}{l}\theta \\
(270, \ldots, 400 \mathrm{~K})\end{array}$ \\
\hline $\begin{array}{l}\text { Physical } \\
\text { parameterizations }\end{array}$ & $\begin{array}{l}\text { hydrological cycle } \\
\text { bound. layer turbulence } \\
\text { radiation scheme } \\
\text { surface model }\end{array}$ & $\begin{array}{l}\text { convective adjustment } \\
\text { bound. layer turbulence } \\
\text { radiation scheme }\end{array}$ & $\begin{array}{l}\text { internal turbulence } \\
\text { surface friction }\end{array}$ \\
\hline Applications & $\begin{array}{l}\text { case studies and tests } \\
\text { (larger domain version } \\
\text { operational since 1991) }\end{array}$ & $\begin{array}{l}36 \mathrm{~h} \text { forecasts } \\
\quad \text { (operational since 1984) }\end{array}$ & $\begin{array}{l}\text { dynamical studies of } \\
\text { airflow near orography, } \\
\text { esp. lee-cyclogenesis }\end{array}$ \\
\hline \multicolumn{4}{|l|}{ For this study } \\
\hline Initialization time & $\begin{array}{l}7 \text { October } 1987 \\
12 \text { UTC }\end{array}$ & $\begin{array}{l}7 \text { October } 1987 \\
12 \text { UTC }\end{array}$ & $\begin{array}{l}8 \text { October } 1987 \\
\text { 00 UTC }\end{array}$ \\
\hline Initial data & from ECMWF analysis & $\begin{array}{l}\text { from BLM analysis } \\
\text { (correction method using } \\
\text { 1st guess and all routine } \\
\text { data) }\end{array}$ & $\begin{array}{l}\text { from real and pseudo- } \\
\text { radiosoundings } \\
\text { (optimum interpolation) }\end{array}$ \\
\hline $\begin{array}{l}\text { Lateral boundary } \\
\text { data }\end{array}$ & $\begin{array}{l}\text { linearly interpolated between } \\
6 \text { hourly ECMWF analyses }\end{array}$ & $\begin{array}{l}\text { linearly interpolated between } \\
3 \text { hourly large scale } \\
\text { predictions }\end{array}$ & $\begin{array}{l}\text { linearly interpolated between } \\
12 \text { hourly analyses }\end{array}$ \\
\hline
\end{tabular}

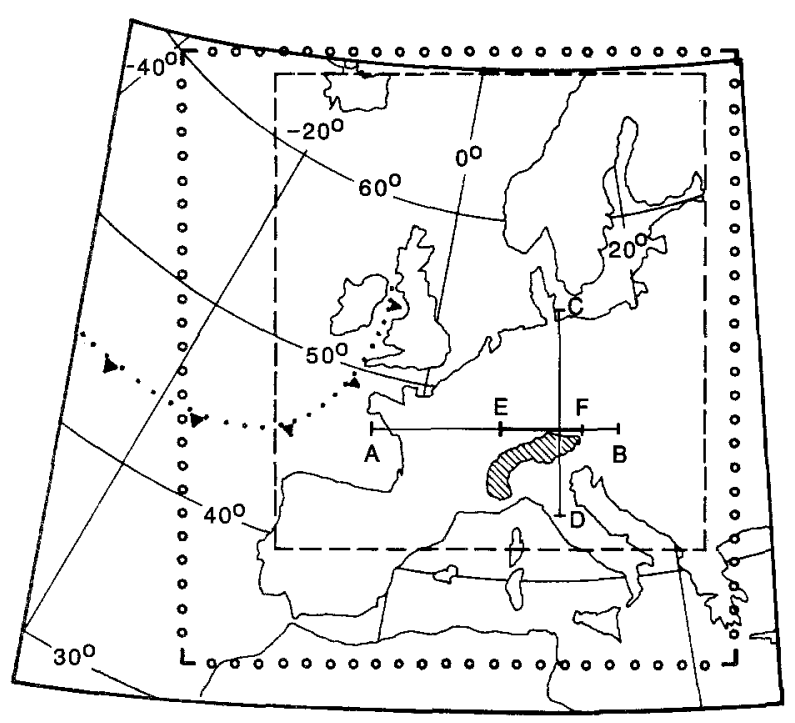

Fig. 1. Outlines of computational domains for EuropaModell (EM, full curved lines), Theta-Surface-Model (TSM, circles), and Boundary-Layer-Model (BLM, dashed lines). The Alpine arc is hatched (EM model orography exceeding $1500 \mathrm{~m}$ ). The letters designate positions of vertical crosssections in Figs. 7, 8, and 11. The dotted line with triangles indicates the surface cold front at 12 UTC, 7 October 1987 which emphasize the hydrological cycle and boundary-layer processes, can be found in Müller et al. (1988); the numerical schemes and the operational version of EM are described in Majewski (1991).

In the operational environment EM is driven by a global model, which provides the lateral boundary values with a 3 hourly update interval. The initial data are taken from a four-dimensional data assimilation, which interpolates the observations onto the EM-grid. For the present case study, however, the initial and boundary values of EM consist of interpolated large-scale ECMWF analyses, which did not take into account the special observations of GFE87. Any mesoscale details in the EM forecast is therefore produced by the forcing from the lower boundary (orography) and by scale interaction during the course of the integration. This applies to the other two models as well.

The Boundary-Layer-Model (BLM) of the Amt für Wehrgeophysik has the longest operational 
experience. It serves as a special purpose model to give prognostic guidance for army, navy and airforce in the lower troposphere up to $36 \mathrm{~h}$ ahead since 1984. The computational grid contains approximately five times fewer gridpoints than EM due to only half the number of vertical levels and a considerably smaller horizontal domain (cf. Fig. 1). The vertical coordinate consists of terrain-following levels ( $\eta$-system) throughout the model height. The model top is situated at $10 \mathrm{~km}$. Moist processes are considered by integration of a transport equation for the water vapour concentration. Details of the model set-up can be found in Prenosil and Becker (1990). A general outline and model results, which include standard BLM output for IOP-A of GFE87, are given by Prenosil et al. (1990).

Initial values for BLM are obtained from an analysis scheme taylored for the model grid, which combines the first guess from a large-scale model with all available routine data by a correction method (cf. Prenosil et al., 1990). The lateral boundary values are interpolated from large-scale forecasts as the results presented here (for the full Alps run) are identical to the routine model output obtained on 8 October 1987.

The isentropic (or $\theta$-) surface model (TSM) differs in several respects from EM and BLM. Originally developed by Bleck (1984) it was modified and extended to simulate lee cyclogeneses as observed during ALPEX (see e.g. Tafferner and Egger, 1990) and is now applied by an university group. For instance, numerical experiments are described by Tafferner and Egger (1992), in which the model Alps and the upper tropospheric forcing was varied for the cases of the papal front (3 May 1987; see also Volkert et al., 1991) and IOP-A of GFE87. The model is dry, i.e. the purely dynamical part of the atmospheric flow is computed. Isentropic surfaces (defined by constant potential temperature) serve as vertical coordinate; this method is claimed to give better
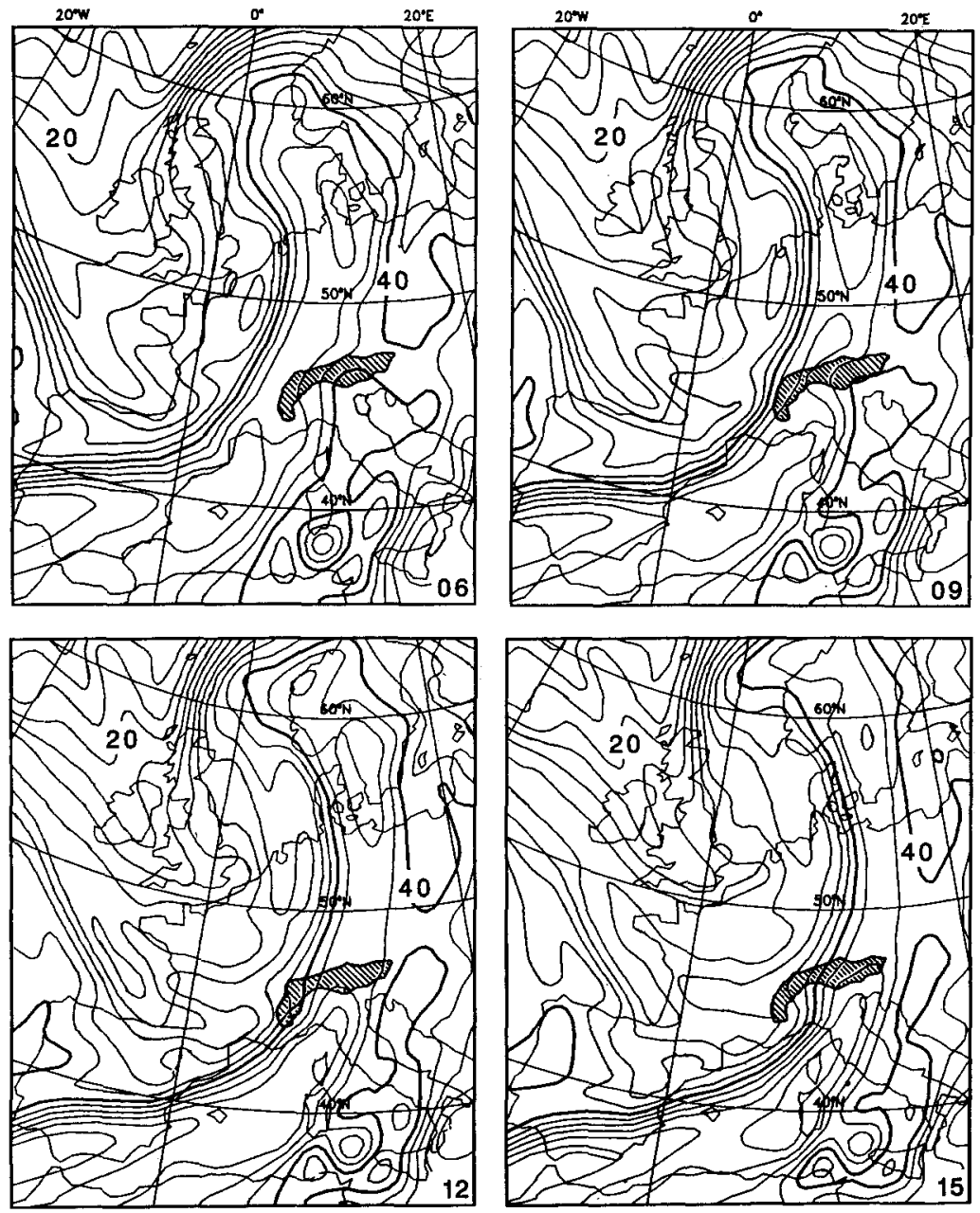

Fig. 2. Equivalent potential temperature predictions of EM on the $700 \mathrm{hPa}$ pressure surface valid for 8 October 1987, 06, 09, 12, and 15 UTC, respectively. Bold isoline: $40^{\circ} \mathrm{C}$; increment: $2.5 \mathrm{~K}$. The Alpine arc is hatched 
resolution in baroclinic zones. A concise outline of TSM is given in Tafferner (1991).

TSM is initialized with data of the operational European rawinsonde network, which are fed into an optimum interpolation type analysis scheme (Bleck, 1975). Initially moisture is taken into account as the analysis is achieved for surfaces of constant virtual potential temperature. The average horizontal resolution $(\overline{\Delta x})$ is a little better than for EM and BLM (Table 1) while the domain boundaries lie between the ones of the other two (Fig. 1). The orography is of the envelope type and derived from a dataset with $5^{\prime}$ zonal and meridinal resolution.

The model orographies have, of course, been tailored for the respective model. Alpine peaks attain 2400 to $2500 \mathrm{~m}$ in all three cases. The Alpine outlines are indicated in Figs. 9 and 10. Displays of the entire orographies can be found in Majewski (1991, Fig. 2a; EM), in Prenosil et al. (1990, Fig. 2; BLM), and in Tafferner (1991, Fig. 2; TSM).

It was not possible to use a common set of initial and boundary data for the present study. For EM and BLM the mentioned initialization schemes were employed and 7 October 1987, 12 UTC was chosen as initial time, which results in 18 to $27 \mathrm{~h}$ forecasts regarding the period of interest. TSM could not be realistically initialized at that time as the frontal structure extending from the Irish Sea in a southwesterly direction and then along the 45th parallel across the Atlantic (cf. Fig. 1) was not resolved by the land based radiosondes. A test run with five "pseudo-soundings" for 7 October, 12 UTC from ECMWF global analyses along the western boundary of the model domain did not provide a correct enough large-scale forcing. Therefore 8 October 1987,00 UTC was chosen as initial time for TSM; the period of interest is covered by 6 to $15 \mathrm{~h}$ TSM-predictions.

All this means that the present study cannot provide a stringent model comparison, but it may well serve as a catalyst to define common initial and boundary datasets for future test applications.

\section{Intercomparison of Model Results and Measure ents}

Here we present basic variables, which directly illustrate the frontal passage near the Alps between 06 and 15 UTC on 8 October 1987, as are distributions of pressure, temperature, potential and equivalent potential temperature. For these fields conventional analyses of radiosonde data are also available. As horizontal levels we chose sea level for pressure (as the vertically integrated signal of the mass field), and two heights for the thermodynamic variables. The lower one is well above the boundary layer except over the Alps themselves $(850 \mathrm{hPa}$ surface for EM and TSM; $1500 \mathrm{~m}$ level for BLM), while the higher one is situated just above the model Alps $(700 \mathrm{hPa}$ for EM and TSM; $3000 \mathrm{~m}$ for BLM). Cross-sections parallel and normal to the eastern Alps show the vertical structure of the thermodynamic variables and the wind component parallel to the mountains. Difference fields of model runs with full and cut-off (at $550 \mathrm{~m}$ ) Alpine orography are used to assess the orographic impact. Finally, EuropaModell data and objectively analysed special measurements are compared in a west-east crosssection north of the Alps.

\subsection{Meso- $\alpha$ Scale Structure of the Front}

During IOP-A the progression of the front as an air mass boundary in the mid-troposphere is well illustrated by the $\theta_{e}$-distribution of EM on the $700 \mathrm{hPa}$ surface for four consecutive times (Fig. 2; for a comparison with a similar conventional analysis on $850 \mathrm{hPa}$ at $00 \mathrm{UTC}$ see Fig. 2b in HV92). A curved, elongated gradient zone (up to $10 \mathrm{~K}$ over $150 \mathrm{~km}$ ) extended from the North Sea over central Europe to Spain. The Alpine arc was touched at 09 UTC. During the following hours the zone started to cross the Alps from west to east. A comparison with the "cut-off Alps run" (not displayed) reveals a slight orographic retardation at 15 UTC, particularly south of the Alps. At the surface the observed frontal deformation was more pronounced (Fig. 3 in HV92) as the surface front lay roughly below the leading edge of the $\theta_{e^{-}}$ gradient zone in $700 \mathrm{hPa}$ at $06 \mathrm{UTC}$, but its eastward progression was faster.

Up to here model output was described as if it were a feature of reality, which appears to be reasonable because of its spatial and temporal coherency. In the following we select 12 UTC as appropriate time for intercomparisons of model results and a conventional manual analysis and use central Europe with a complete coverage of the Alps as the region of interest. 

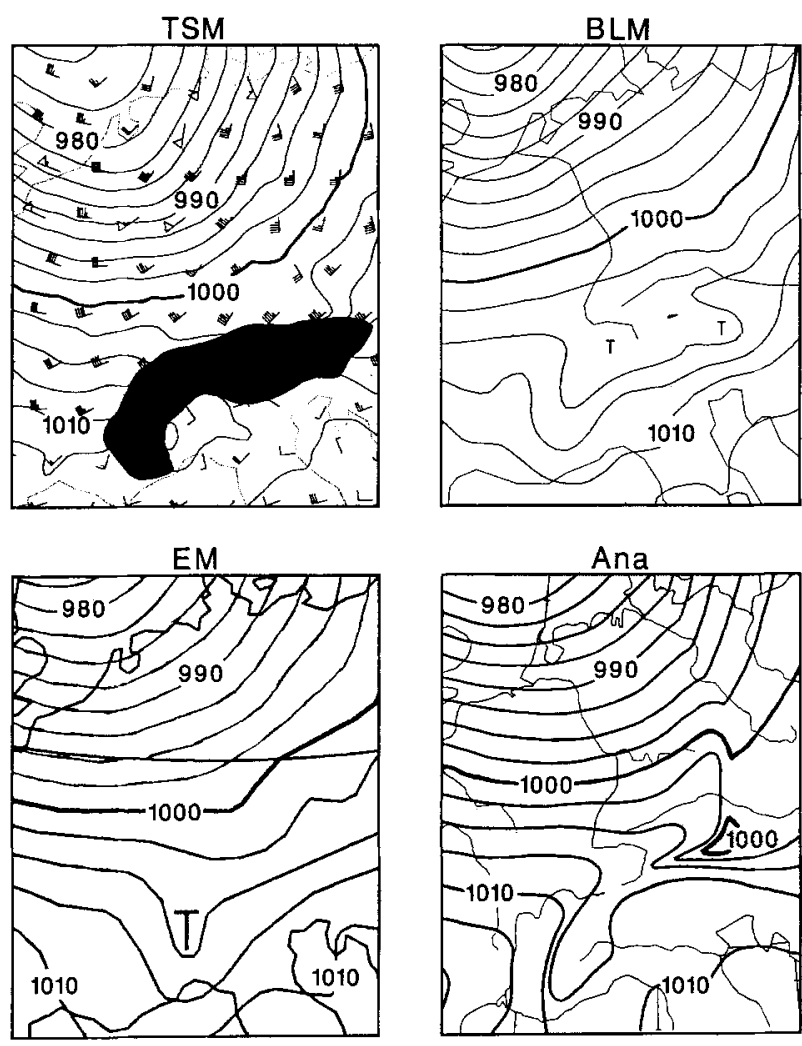

Fig. 3. Sea level pressure valid for 8 October 1987, 12 UTC. Model acronyms as in Fig. 1; Ana: verifying analysis. Increment: $2.5 \mathrm{hPa}$. TSM also contains computed surface winds (standard notation in knots) and blacked out model Alps (heights exceeding $1200 \mathrm{~m}$ )

Predictions and analysis of sea level pressure are juxtaposed in Fig. 3. A north-south pressure gradient (more than $30 \mathrm{hPa}$ difference from the North Sea to the Lions Gulf) is the prominent feature. South of the river Danube a mesoscale depression (foehn low; cf. Fig. 14 in HV92) is embedded just ahead of the analysed isoline kinks, which indicate the surface front position. All three models produce the synoptic-scale trough. EM and BLM predict the absolute values correctly (e.g. $980 \mathrm{hPa}$ isobar over the North Sea), whereas TSM overestimates the pressure gradient over western Germany and, consequently, the surface winds (wind analysis not displayed). Signs of a mesoscale pressure anomaly to the north of the Alps are apparent in TSM and BLM. The model resolution can be deduced from the surface wind arrows in TSM as an arrow is displayed for every third gridpoint in both directions. Not simulated by all models is the marked ridge behind the front over southern Germany.
Figure 4 shows the temperature field at $1500 \mathrm{~m}$ or $850 \mathrm{hPa}$ in the same fashion. The enhanced radiosonde density in southern Germany due to GFE87 made it possible to resolve the frontal temperature gradient particularly well north of the Alps. The models are not able to account for the strong gradient of up to $6 \mathrm{~K}$ over $100 \mathrm{~km}$. TSM gives the best thermal structure but is systematically too warm by $2 \mathrm{~K}$ north of the Alps, BLM exhibits the strongest gradient across the region of the upper Rhine valley, whereas EM shows a curved, but more uniform gradient zone across the whole of central Europe. The reason for this discrepancy could be the too slow progression of cold air $\left(850 \mathrm{hPa}\right.$ temperatures around $\left.6^{\circ} \mathrm{C}\right)$ behind the front in all the models.

The next comparison is for potential temperature $(\theta)$ at $3000 \mathrm{~m}$ or $700 \mathrm{hPa}$ (Fig. 5). The strongest analysed gradient lies over the upper Rhine area; a mesoscale cool anomaly is found south of the
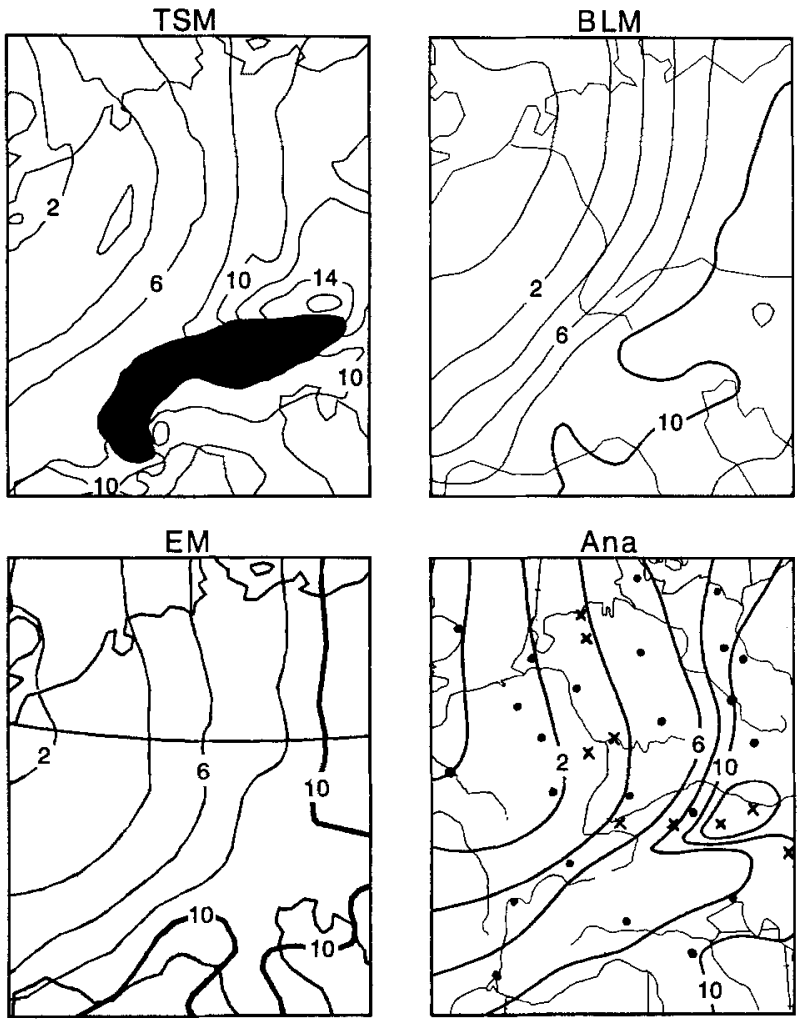

Fig. 4. Temperature $\left({ }^{\circ} \mathrm{C}\right)$ in the $850 \mathrm{hPa}$ (TSM, EM, Ana) and $1500 \mathrm{~m}$ level (BLM) valid for 8 October 1987, 12 UTC. Model acronyms as in Fig. 1; Ana: verifying analysis with regular (dots) and special (crosses) sounding stations; increment: $2 \mathrm{~K}$. TSM also contains blacked out model Alps (heights exceeding $1500 \mathrm{~m}$ ) 

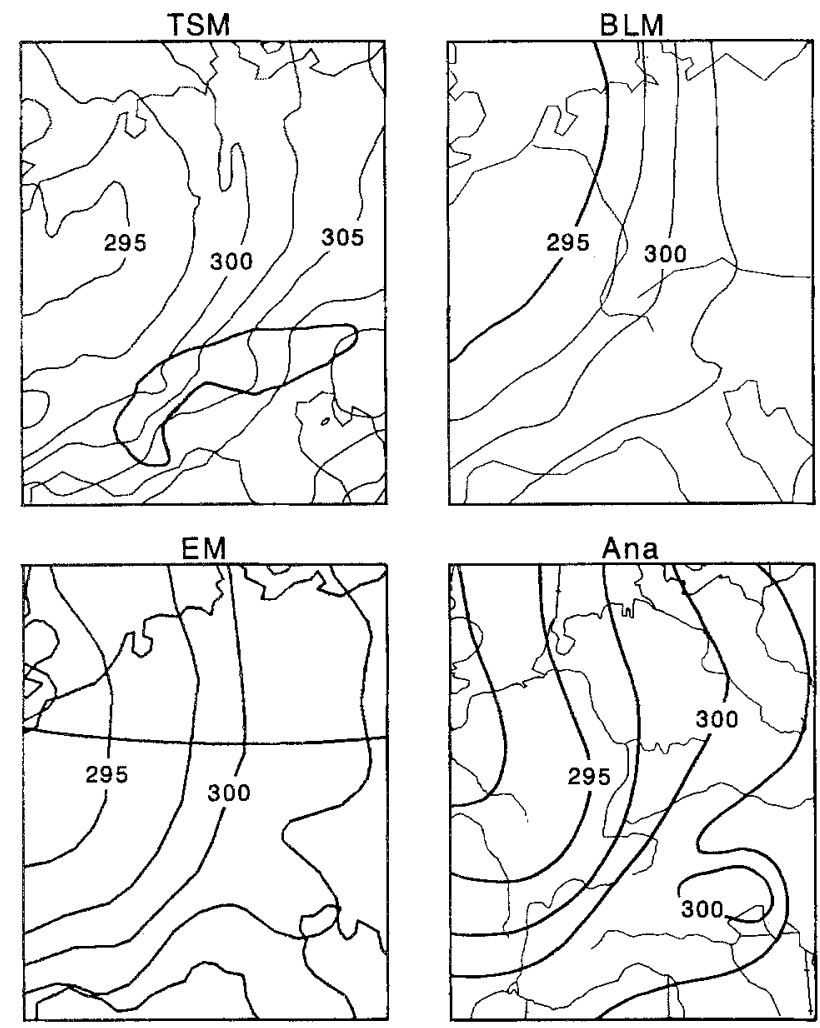

Fig. 5. Potential temperature in the $700 \mathrm{hPa}$ (TSM, EM, Ana) and $3000 \mathrm{~m}$ level (BLM) valid for 8 October 1987,12 UTC. Model acronyms as in Fig. 1; Ana: verifying analysis; increment: $2.5 \mathrm{~K}$. TSM also contains Alpine outline (heights equal to $1500 \mathrm{~m}$ )

eastern Alps. The position of the maximum gradient zone is captured well by all three models.

Because cold fronts tend to be marked not only by a temperature contrast but by differences in humidity as well, equivalent potential temperature $\left(\theta_{e}\right)$ is often used as a more appropriate airmass marker as it combines both effects. This quantity is displayed in Fig. 6 (except for TSM, which does not contain moisture), again for the $3000 \mathrm{~m}$ or $700 \mathrm{hPa}$ level. Above the upper Rhine region, the analysed gradient in $\theta_{e}(10 \mathrm{~K}$ over $100 \mathrm{~km})$ is more than twice as strong as the one in $\theta$. A mesoscale cool anomaly is found over northern Germany and a warm anomaly over sourthern-eastern Germany can be resolved. BLM and EM predict the enhanced gradient zone in $\theta_{e}$ very well and even some of the analysed mesoscale features are present, although not consistently (BLM: gradient over the upper Rhine area exactly correct, but too high $\theta_{e}$-values along the eastern edge; EM: signs of the north German cool anomaly, but too high values over the British Channel). The eastward advancement, relative to the analysis, of the frontal zone in BLM and its distinct change in direction over the western part of the Danube is regarded as an effect due to the model Alps, which is apparently overestimated in this case.

The foregoing comparisons are certainly not strict in the sense that they give direct hints to specific model deficiencies. Their usefulness (and as far as we are aware novelty) lies in the fact that output of different models and analyses have been made directly comparable by choosing the same area and identical isoline values for various variables. As general conclusion we state that all models are able to simulate rather well the thermodynamical contrast, which was associated with the front of 8 October 1987. Of course, details of horizontal extents of a couple of gridsizes or less cannot be resolved. The discrepancies between the models themselves and compared with the analysis are most obvious close to the Alps.

Next, we inspect vertical cross-sections, which are rarely used in routine analyses but give valuable insights if their position is well chosen. The progression of the front along the Alps and roughly

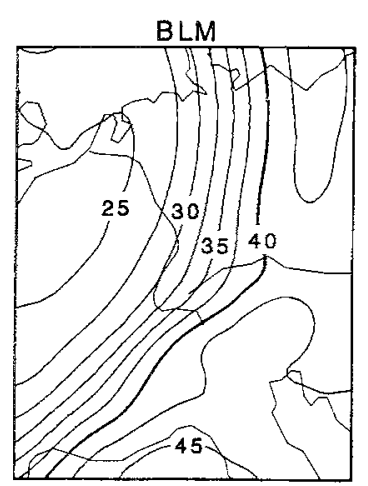

Qe $\{3 \mathrm{~km})$

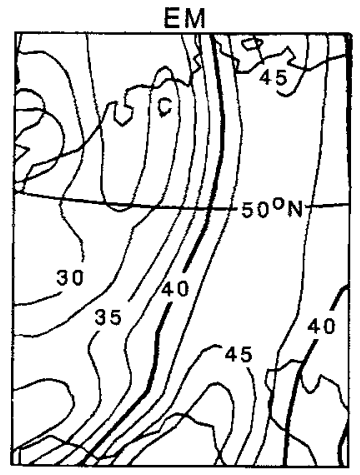

Qe $(700 \mathrm{hPa})$

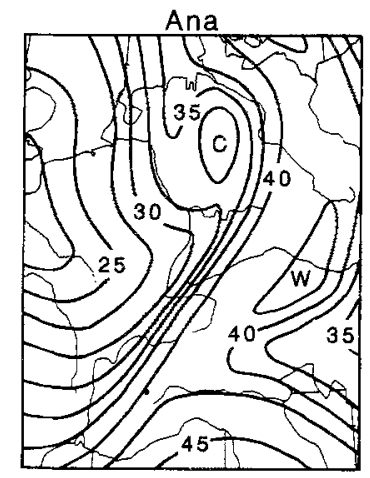

Qe $(700 \mathrm{hPa})$
Fig. 6. Equivalent potential temperature $\left({ }^{\circ} \mathrm{C}\right)$ in the $700 \mathrm{hPa}(\mathrm{EM}, \mathrm{Ana})$ and $3000 \mathrm{~m}$ level (BLM) valid for 8 October 1987, 12 UTC. Model acronyms as in Fig. 1; Ana: verifying analysis; increment: $2.5 \mathrm{~K}$ 

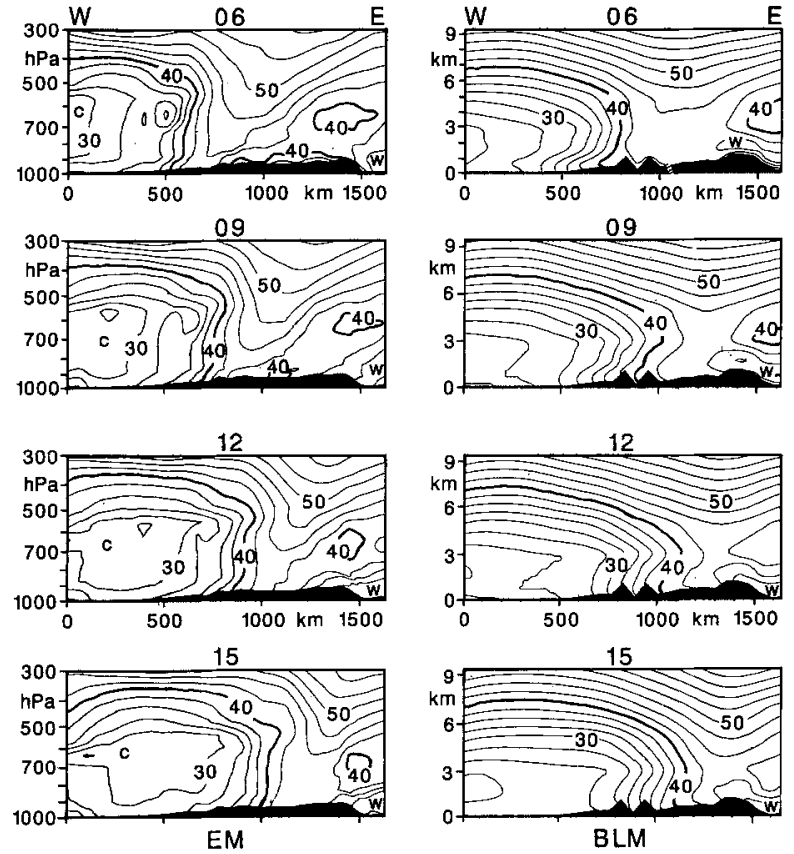

Fig. 7. West-east cross-sections of equivalent potential temperature $\left({ }^{\circ} \mathrm{C}\right.$ ) computed by EM (left) and BLM (right) for 8 October 1987, 06, 09, 12, 15 UTC. The section runs along line $\mathrm{AB}$ in Fig. 1. Increment: $2.5 \mathrm{~K}$

normal to its orientation (line $A B$ of Fig. 1) is depicted in Fig. 7, visualized by four consecutive $\theta_{e}$-sections for EM and BLM. In both models it is evident that a massive body of cool and dry air (reaching up to $500 \mathrm{hPa}$ ) follows a distinct, nearly vertical frontal zone, at the warm end of which the surface front is located. The existence of a surface based cool air pool ahead of the front at 06 and 09 UTC (foehn inversion; cf. HV92) is captured, particularly by EM. A more detailed discussion including comparisons with measurements is given in section 3.3. At all times, EM contains more fine scale structure than BLM, probably because more physical processes are included in the model formulation. Moreover, differences in the specification of the model orographies are apparent.

\subsection{Orographic Impact}

A special advantage of model simulations lies in the possiblity to carry through numerical experiments with and without certain model features. Here, we attempt to isolate the impact which the Alps exert on the atmosphere by aid of a control run where Alpine heights exceeding $550 \mathrm{~m}$ were removed.
A north-south section of $\theta$ across the Alps (line $\mathrm{CD}$ in Fig. 1) is given in Fig. 24 of Egger and Hoinka (1992). In TSM and EM a hydrostatic wave due to the orography is evident, whereas the Alpine influence on the $\theta$-field is much weaker in BLM. The evolution of the wind component normal to a section $150 \mathrm{~km}$ further to the west (right over the top of the eastern model Alps) and roughly normal to the front is displayed in Fig. 8 as computed by TSM. A comparison of the "full Alps results" with difference fields reveals that a good deal (approximately $5 \mathrm{~m} / \mathrm{s}$ ) of the velocity maximum on the northern side of the Alps and below crest height is due to the orography. But it has to be admitted that the strong surface wind north of the full model Alps is considerably higher than it was observed.

Next, we turn to differences apparent in horizontal fields. It is climatologically well established that trans-Alpine foehn flows induce a mesoscale depression in the lee of the Alps as well as a rise in temperature (see e.g. Volkert, 1983, Fig. 23). As foehn occurred ahead of the front, we inspect difference fields valid for 8 October 1987, 09 UTC.

The orographic pressure reductions vary from maximal $-7 \mathrm{hPa}$ (TSM) over $-3.5 \mathrm{hPa}(\mathrm{BLM})$ to $-2.5 \mathrm{hPa}$ (EM; Fig. 9). The position of the anomalies relative to the respective model Alps differs considerably. For BLM the area of reduced pressure covers the entire Alps, while TSM and EM show increased pressure over the French Alps (blocking effect) and a relative depression on the lee side.

The same holds for temperature in $1500 \mathrm{~m}$ or $850 \mathrm{hPa}$ (Fig. 10). TSM gives a warming by $6 \mathrm{~K}$ over Bavaria, EM one by $4 \mathrm{~K}$ much further to north-east, while the anomaly in BLM is more or less centred over the Alps.

This variability in orographically induced anomalies regarding the different models points to intrinsic differences concerning the treatment of mountains in the model equations. The different spatial extent of the three kinds of model Alps as apparent from Fig. 10 appears to be only of secondary importance.

\subsection{Meso- $\beta$ Scale Details North of the Alps}

During GFE87 radiosondes were released in southern Germany and the adjacent regions of Austria and Switzerland at more places and more 
full Alps
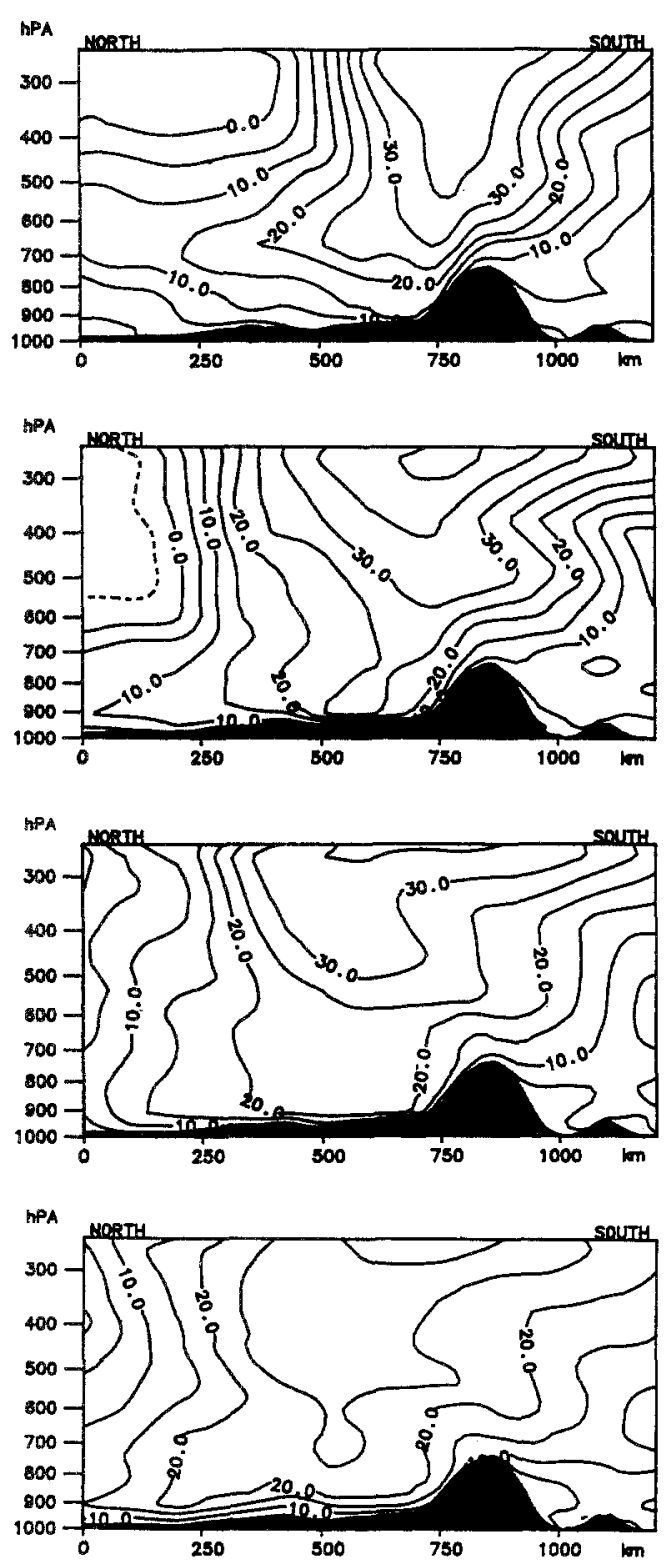

difference

06
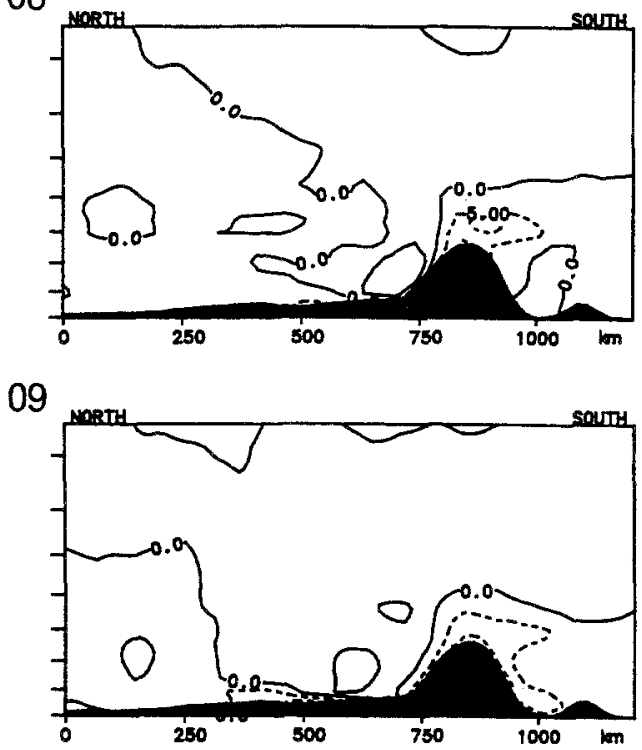

12

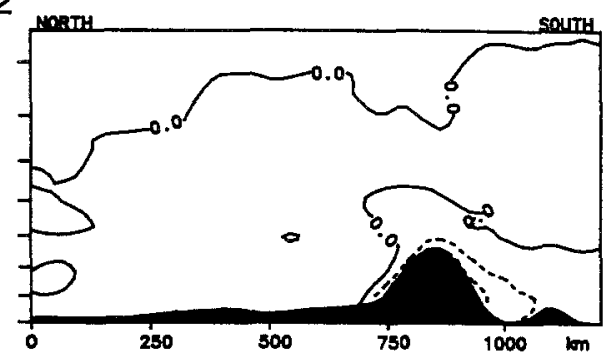

15

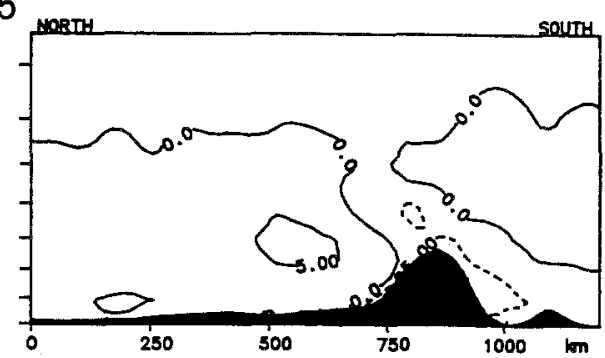

Fig. 8. North-south cross-sections of wind component normal to the plane (m/s) computed by TSM for 8 October 1987,06 , 09, 12, 15 UTC (left) and of Alpine disturbance, e.g. difference of run with full Alps minus run with cut-off Alps (right). The section runs parallel to the line CD in Fig. 1, but $150 \mathrm{~km}$ to the west. Increment: $5 \mathrm{~m} / \mathrm{s}$
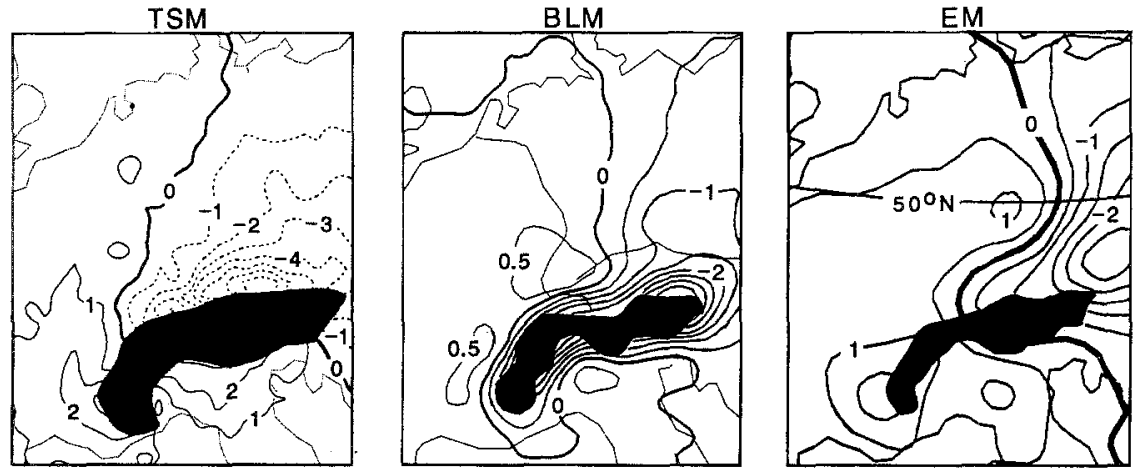

Fig. 9. Orographic impact on sea level pressure for 8 October 1987, 09 UTC: difference of run with full Alps minus run with cut-off Alps. Model acronyms as in Fig. 1. Increment: $1 \mathrm{hPa}$ (TSM) and $0.5 \mathrm{hPa}$ (BLM and EM). Model orographies black for heights exceeding $1200 \mathrm{~m}$ (TSM) and 1500 (BLM, EM) 

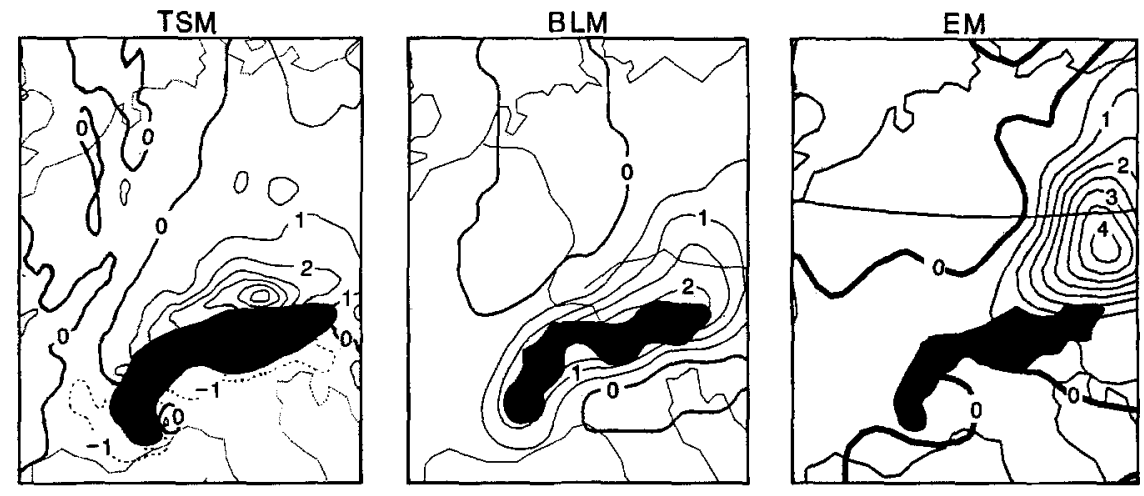

Fig. 10. Orographic impact on temperature in the $850 \mathrm{hPa}$ (TSM, EM) and $1500 \mathrm{~m}$ level (BLM) for 8 October 1987, 09 UTC: difference of run with full Alps minus run with cut-off Alps. Model acronyms as in Fig. 1. Increment: $1 \mathrm{~K}$ (TSM) and $0.5 \mathrm{~K}$ (BLM and EM). Model orographies black for heights exceeding $1500 \mathrm{~m}$

often than is regularly the case (for a complete list of locations and release times see Hoinka et al., 1988). This dataset enabled objective analyses of the measured variables onto a regular grid, on which derived quantities, as $\theta_{e}$, and those containing derivatives, as vorticity, can be calculated (cf. Thorpe et al., 1992).

For a detailed west-east section across southern Germany (line EF in Fig. 1) analysed $\theta_{e}$ is compared to $\theta_{e}$ computed by EM at four consecutive times. At 06 UTC the cool and dry post-frontal air $\left(\theta_{e}<40^{\circ} \mathrm{C}\right)$ was still outside the western edge, but a cool pool (foehn inversion) with $\theta_{e}$ below $35^{\circ} \mathrm{C}$ was situated below $800 \mathrm{hPa}$ in the eastern half of the section. By 09 UTC the front had entered the section, relicts of the cool pool remained and a funnel of potentially warmer (and moister) air got squeezed between the other two features, which in turn exhibited increased gradients at their edges. At 12 UTC the pre-frontal foehn inversion had disappeared and the post-frontal air continued to progress further to the east. It has to be noted that the horizontal positioning within the objective analysis scheme is only accurate to about $80 \mathrm{~km}$, due to an average distance between the soundings of that order and to imperfect synchronization of the release times.

Europa-Modell output of $\theta_{e}$ for the same section and times exhibits a remarkable agreement with the features just described. The foehn inversion is
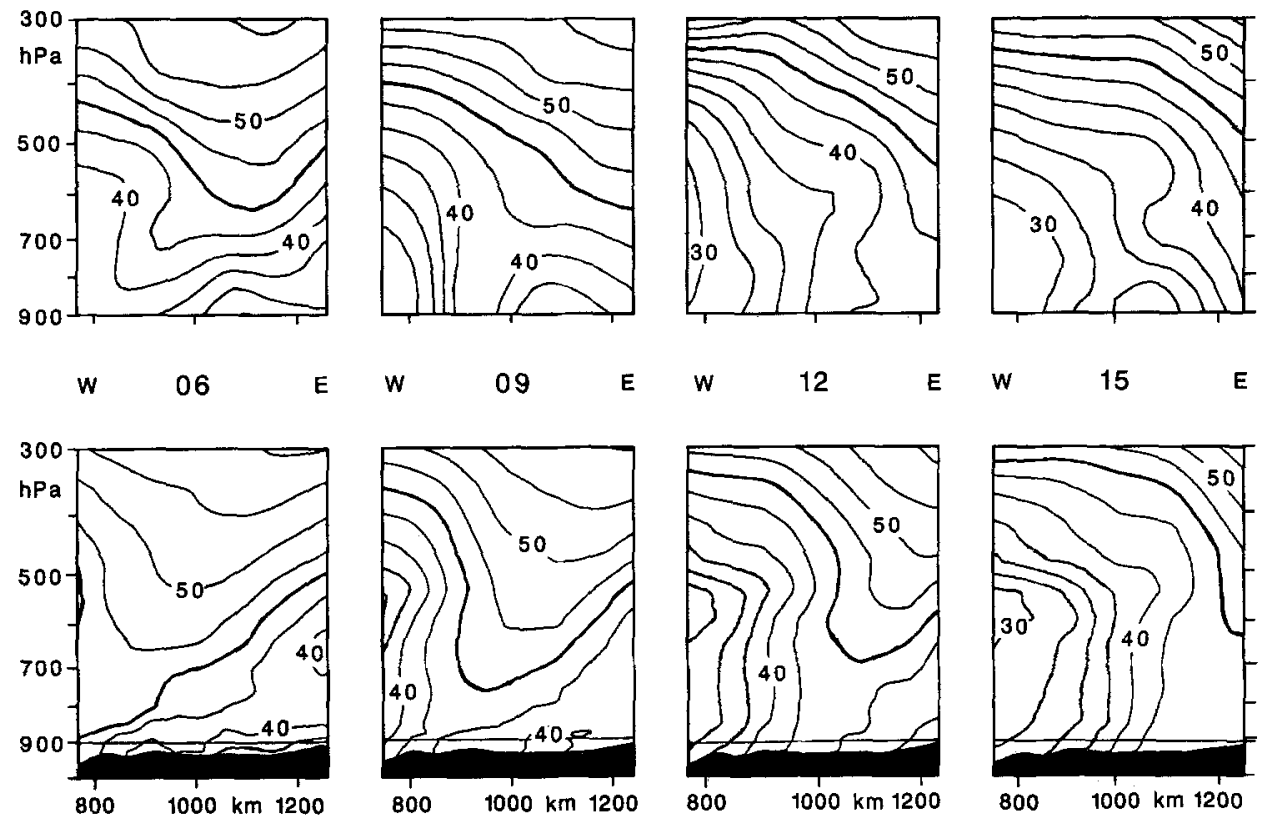

Fig. 11. West-east cross-sections of equivalent potential temperature $\left({ }^{\circ} \mathrm{C}\right)$ for 8 October $1987,06,09,12,15$ UTC. Objectively diagnosed data from a dense radiosonde network (top) and computed by EM (bottom). The section runs along line EF in Fig. 1. Increment: $2.5 \mathrm{~K}$ 
present at 06 UTC, the frontal zone enters the section at 09 UTC with inversion relicts remaining, even the funnel is present. A comparison with Fig. 7 reveals that BLM predicts the frontal zone even closer to the observations, but does not resolve the pre-frontal foehn inversion. The model data exhibit greater temporal coherence with regard to the frontal gradient, whereas the measurements represent fully independent samples. A more detailed discussion about these structures in $\theta_{e}$ can be found in Heimann (1992). Similar crosssections through four maritime cold fronts west of Brittany were recently evaluated from dropsonde data of even finer mesoscale resolution (Thorpe and Clough, 1991); they exhibit significantly stronger gradients in $\theta_{e}$.

In conclusion we note that the good agreement between model output and objective analyses has to be considered as an important cross-validation of analysis method and numerical model; or more generally, only a combination of independent tools can provide confidence in the results of phenomenological data studies of mesoscale fields at levels above the surface.

\section{Concluding Remarks}

Three areas were mentioned in section 1 , which motivated this study. What résumé can be drawn? Firstly, the applied regional models successfully simulated the synoptic-scale thermodynamical structure of the front of 8 October 1987 as far as can be judged from the comparisons with data analyses. However, the mesoscale behaviour of the front north of the Alps was not predicted in a satisfactory fashion. In particular, the strengthening of the temperature gradient through confluence of cold air intruding from the west with warm foehn air and the resulting acceleration of the front (cf. Kurz, 1989, 1990) were not captured by the models. As possible reasons for this failure we mention improper treatment of orographic effects in the models or insufficient mesoscale information in the initial fields. A thorough assessment of the impact of denser than routine data on the model performance (especially over the Alpine region) has still to be accomplished. To approach this aim, which was already formulated during the planning phase of ALPEX, a dataset is needed of greater spatial extent than the ones obtained during GFE87. Its temporal extent must match the length of a forecast period, i.e. it has to cover at least $24 \mathrm{~h}$.

Secondly, the potential of the models as research tools was exemplified. Charts of primary and derived quantities illustrated, for instance, the progression of the front. Difference fields revealed that the orographic impact is sensitive to the specific model formulation. What is still lacking are diagnostic studies using the model data, e.g. concerning the various terms of the frontogenesis function as estimated by Kurz (1990) from observed data or with regard to vorticity and potential vorticity as diagnosed by Thorpe et al. (1992).

Finally, the applied models are to be compared. A quantitative ranking is not possible, partly because no common set of initial and boundary data was available. Yet, the horizontal charts (Figs. 2-6) indicate in particular the ability of EM and BLM to produce smooth thermodynamical gradient zones, which may be explained by the consistent forcing through a large-scale model and, possibly, successful fine tuning through operational experience. Moisture effects contributed significantly to the frontal gradients as it was also analysed. The performance of BLM is remarkable regarding its smaller horizontal extent and coarser vertical resolution. EM produces finer scale structures, the realism of which was corroborated in a vertical cross-section with objective data analyses. The purely thermal contrasts (apparent through gradients in $\theta$ ) are stronger in TSM than in BLM and $\mathrm{EM}$, probably because of the use of isentropic coordinates.

In summary we note that both operational models possess a particular potential for being used as research tools beside their primary objective of producing real-time forecasts. The limited scope of this study clearly should be enlarged in the future, but so far even a simple juxtaposition of output from different models and analysed data in a common layout was not available for central Europe. Numerical experiments with a common set of initial and boundary data are necessary for a thorough cross-validation of the models. EM is particularly suited for testing the impact of the various parameterized physical processes on the evolution of mesoscale structures. Future field campaigns should be designed in close co-operation with the modelling teams within the weather services, as it is obvious that case studies using a regional model are a valuable supplement for investigations which sofar were entirely based on 
observations. With regard to the German Front Experiment 1987 the cases of IOPs B, C, and D await their simulations.

\section{Acknowledgements}

J. Egger (Universität München) is thanked for encouraging the coordinated effort of bringing together the three modelling teams which contributed predictions to this study after having started independently. M. Pedder (Reading University) and S. Clough (UK Meteorological Office) made available software for objectively diagnosing and conveniently displaying the data shown in Fig. 11 (top). Their generous support is gratefully acknowledged. J. Freund and G. Steudel (both DLR) competently assisted in bringing the model output to a comparable size and in finalizing the figures.

\section{References}

Anthes, R. A., 1983: Regional models of the atmosphere in middle latitudes. Mon. Wea. Rev., 111, 1306-1337.

Arpe, K., Hollingsworth, A., Tracton, M. S., Lorenc, A. C., Uppala, S., Kallberg, P., 1985: The response of numerical weather prediction systems to FGGE level IIb data. Part II: forecast verifications and implications for predictability. Q. J. R. Meteorol. Soc., 111, 67-102.

Ballard, S. P., Golding, B. W., Smith, R. N. B., 1991: Mesoscale model experimental forecasts of the Haar of northeast Scotland. Mon. Wea. Rev., 119, 2107-2121.

Bougeault, P., Bret, B., Lacarrère, P., Noilhan, J., 1991: An experiment with an advanced surface parameterization in a mesobeta-scale model. Part II: the 16 June 1986 simulation. Mon. Wea. Rev., 119, 2374-2392.

Bleck, R., 1975: An economical approach to the use of wind data in the optimum interpolation of geo- and Montgomery potential fields. Mon. Wea. Rev., 103, 807-816.

Bleck, R., 1984: An isentropic coordinate model suitable for lee cyclogenesis simulation. Riv. Meteorol. Aeronaut., 44, 189-194.

Egger, J., 1985: DFG-Schwerpunktprogramm "Fronten und Orographie". In K. P. Hoinka und H. Volkert, 1987: Das deutsche Frontexperiment 1987 - Experimentplan. DFVLRMitt. 87-24, 43-48.

Egger, J., Hoinka, K. P., 1992: Fronts and orography. Meteorol. Atmos. Phys., 48, 3-36.

Grønås, S., 1989: High resolution operational models in mesoscale meteorology. Proceed. of IAMAP '89, Vol. I, University of Reading, review paper MF.R5, pp. MF 24-28.

Heimann, D., 1990: Three-dimensional modeling of synthetic cold fronts approaching the Alps. Meteorol. Atmos. Phys., 42, 197-219.

Heimann, D., 1992: Potential and equivalent-potential temperature patterns at cold fronts with pre-frontal foehn. Meteorol. Atmos. Phys., 48, 165-171.

Hoinka, K. P., Hagen, M., Volkert, H., Heimann, D., 1990: On the influence of the Alps on a cold front. Tellus, 42A, $140-164$.
Hoinka, K. P., Volkert, H., Heimann, D., 1988: The German Front Experiment: observations and preliminary results. DFVLR-Forsch. bericht 88-21, 133 pp.

Hoinka, K. P., Volkert, H., 1992: Fronts and the alps: findings from the Front Experiment 1987. Meteorol. Atmos. Phys., 48, 51-75.

Keyser, D., Uccellini, L., 1987: Regional models: emerging research tools for synoptic meteorologists. Bull. Amer. Meteor. Soc., 68, 306-320.

Kuettner, J. P., (ed.), 1982: ALPEX - experiment design. GARP-ALPEX Publication No. 1, WMO, Geneva, 302 pp.

Kurz, M., 1989: Zur Analyse und Diagnose der ersten beiden Fronten des Frontenexperiments der Deutschen Forschungsgemeinschaft (DFG). Meteorol. Rdsch., 41, $147-160$.

Kurz, M., 1990: The influence of the Alps on structure and behaviour of cold fronts over southern Germany. Meteorol. Atmos. Phys., 43, 61-68.

Majewski, D., 1991: The Europa-Modell of the Deutscher Wetterdienst. Proceed. of ECMWF-Seminar "Numerical methods in atmospheric models", Vol. II, Reading, 9-13 September 1991, 147-191.

McCallum, E., Grant, J. R., Golding, B. W., 1983: A synoptic case-study using a numerical model. Meteorol. Magazine, 112, 275-288.

Müller, E., Frühwald, D., Jacobsen, I., Link, A., Majewski, D., Schwirner, J. U., Wacker, U., 1988: Results and prospects of mesoscale modeling at the Deutscher Wetterdienst. J. Jap. Meteorol. Soc., special issue, 533-546.

Prenosil, T., Becker, H. G., 1990: Das "Boundary Layer" Modell des Geophysikalischen Beratungsdienstes der Bundeswehr-ein regionales Wettervorhersagesystem. Fachliche Mitteilung Nr. 211, Amt für Wehrgeophysik, Traben-Trarbach, ISSN 0342-6025.

Prenosil, T., Dedenbach, D., Koschnick, W., Becker, G., 1990: Das regionale Wettervorhersagesystem BLM. Promet, 20 (1/2), 1-17.

Simmons, A. J., Burridge, D. M., 1981: An energy and angular-momentum conserving vertical differencing scheme and hybrid vertical coordinates. Mon. Wea. Rev., 109, 758-766.

Tafferner, A., 1991: Numerische Simulation der Leezyklogenese. Promet, 21 (3/4), 89-100.

Tafferner, A., Egger, J., 1990: Test of theories of lee cyclogenesis: ALPEX cases. J. Atmos. Sci., 47, 24172428.

Tafferner, A., Egger, J., 1992: Modification of fronts by the Alps: simulations and numerical experimentation. Meteorol. Atmos. Phys., 48, 193-203.

Thorpe, A. J., Clough, S. A., 1991: Mesoscale dynamics of cold fronts: structures described by dropsoundings in Fronts87. Q. J. R. Meteorol. Soc., 117, 903-941.

Thorpe, A. J., Volkert, H., Heimann, D., 1992: Mesoscale dynamics of flow along the Alps. Q. J.R. Meteorol. Soc. (submitted).

Volkert, H., 1983: Klimatologie der Varianz meteorologischer Felder in Südbayern. Dissertation Univ. München, DFVLR-Forsch. bericht 83-31, 154 pp. 
Volkert, H., Weickmann, L., Tafferner, A., 1991: The 'papal front' of 3 May 1987 - a remarkable example of frontogenesis near the Alps. Q. J. R. Meteorol. Soc., 117, 125-150.

WMO, 1988: Report of the second international cloud modelling workshop. WMO Technical Document No. 268, Geneva, 330 pp.

Authors' addresses: Dr. Hans Volkert, Institut für Physik der Atmosphäre, DLR Oberpfaffenhofen, D-W-8031 WeBling,
Federal Republic of Germany; Dipl.-Met. Manfred Kurz, Deutscher Wetterdienst, Zentralamt, Abt. Synoptik, Postfach 100465 , D-W-6050 Offenbach am Main, Federal Republic of Germany; Dipl.-Met. Detlev Majewski, Deutscher Wetterdienst, Zentralamt, Abt. Forschung, Postfach 100465 , D-W6050 Offenbach am Main, Federal Republic of Germany; Dr. Thomas Prenosil, Amt für Wehrgeophysik, Mont Royal, D-W-5580 Traben-Trarbach, Federal Republic of Germany and Dr. Arnold Tafferner, Meteorologisches Institut der Universität München, Theresienstraße 37, D-W-8000 München 2, Federal Republic of Germany. 